\title{
Importance of the Numerical Representation of Shallow and Deep Convection for Simulations of Dust Transport over a Desert Region
}

\author{
Tetsuya Takemi \\ Disaster Prevention Research Institute, Kyoto University, Gokasho, Uji, Kyoto 611-0011, Japan \\ Correspondence should be addressed to Tetsuya Takemi, takemi@storm.dpri.kyoto-u.ac.jp
}

Received 18 January 2012; Accepted 11 March 2012

Academic Editor: Dimitris G. Kaskaoutis

Copyright () 2012 Tetsuya Takemi. This is an open access article distributed under the Creative Commons Attribution License, which permits unrestricted use, distribution, and reproduction in any medium, provided the original work is properly cited.

\begin{abstract}
This study examines the representations of shallow and deep convection under two distinct stability conditions over a desert region with the use of the numerical outputs from large-eddy simulations at the $100 \mathrm{~m}$ horizontal resolution. The numerical experiments were set up under idealized conditions of a horizontally uniform basic state over a homogeneous and flat surface, which was aimed at representing fair-weather convective situations over the Gobi Desert. Spatial spectra were used in order to examine how small scales are reproduced and how representative scales appear at various heights. From the results of the spectral analyses, a grid scale required to properly represent shallow and deep convection in convection-resolving simulations is identified. It is indicated that the adequate representations of shallow and deep convection are critically important in simulating the transport of dust aerosols under convective conditions.
\end{abstract}

\section{Introduction}

The transport of airborne materials such as mineral dust, pollen, anthropogenic pollutants, and radioactive materials is strongly affected by atmospheric conditions and weather disturbances. From a global scale and a synoptic scale point of view, global circulation, tropical and extratropical cyclones, cold/warm/stationary fronts, and mesoscale circulations with a spatial scale of greater than the order of $100 \mathrm{~km}$ play major roles in determining the transport of such atmospheric tracers. In contrast, the roles played by turbulent eddies, boundary-layer convection, cumulus convection, and cumulonimbus clouds become critical in tracer transports at a scale of the order of $10 \mathrm{~km}$ or less under convectively unstable conditions. Since convection induces vertical motions much greater than those due to a global scale, a synoptic scale, and a mesoscale circulation, convective updrafts and downdrafts have a dominant influence on the vertical transport of tracers. It was argued that well-developed planetary boundary layer (PBL), which leads to the formation of cumulus clouds, plays a role in controlling the transport of tracers upward above the PBL [1].
Convective motions at various spatial scales in the horizontal and vertical directions, that is, shallow convection (boundary-layer convection and low-topped cumulus cloud) and deep convection (high-topped cumulus cloud and cumulonimbus), are widespread phenomena especially over arid and semiarid regions since the ground surface is strongly heated during the daytime. Considering that the ground surfaces over arid and semiarid regions are rich in the abundance of mineral dust particles and that those regions are the source of dust aerosols globally $[2,3]$, the effects of vertical motion due to convection should be adequately evaluated in examining the transport of mineral dust aerosols not only at the local scales but also at global scales. Therefore, it is critically important to represent processes due to shallow and deep convection in the numerical simulations of dust transport over desert regions. This study aims at investigating the numerical representations of shallow and deep convection in a spatial resolution of the order of $100 \mathrm{~m}$ to $1 \mathrm{~km}$ for the applications to transport simulations.

There are studies that pointed out the importance of convective scales in considering dust transport in the atmosphere. Luo et al. [4] indicated that the diurnal variability 
of dust mobilization and concentration, due mostly to convective activity, accounts for 20 to $80 \%$ of the total temporal variability depending on the geographical region. Koch and Renno [5] theoretically evaluated that boundarylayer convective motion contributes to about $35 \%$ of the global dust budget. Such convective activity was shown to account for the trans-Pacific transport of aerosols from East Asia to the North American west coast by the vertical injection from the PBL [6]. Yasui et al. [7, 8] examined the vertical profile of dust aerosols from the data obtained by lidar observations over the Gobi Desert and showed that the diurnal variation of dust contents in the lower atmosphere is closely related to the variability of PBL. Owing to deep thickness of the PBLs over desert regions $[9,10]$, dust transport from the boundary layer to the free atmosphere is considered to be effectively processed by convective motions.

Although the importance of convective scales in considering dust transport over desert regions is generally recognized in the previous studies mentioned above and also in the global modeling studies $[11,12]$, the convectivescale processes are not properly represented in most of the numerical modeling studies on dust transport at global and regional scales. This is largely due to the limitation of computational costs. On the other hand, it is considered to be critically important to represent and/or parameterize microscale eddies in the modeling of convection and transport phenomena for quantitatively evaluating the amount of the emission, advection, dispersion, and deposition of airborne materials.

Convection-resolving simulations have long been pursued in order to adequately represent convective scales under various atmospheric conditions including convectively unstable states not only in the research community but also in the operational forecasting community. Convectionresolving simulations are originally intended to explicitly resolve convective clouds and are performed with a horizontal grid spacing typically on the order of $1 \mathrm{~km}$ [13]. Such a resolution should be critically important in considering not only convective weather phenomena but also transport phenomena in convective conditions, for example, dust distribution over desert regions.

The choice of the grid spacing in convection-resolving simulations is considered to be based on the thought that the scale should be sufficient to resolve convective clouds whose scales are on the order of $10 \mathrm{~km}$. Weisman et al. [14] showed that the upper limit of the grid scale that can represent convective features of mesoscale convective systems is about $4 \mathrm{~km}$ from a viewpoint of nonhydrostatic dynamics.

On the other hand, it has recently been argued that convection-resolving simulations may not always sufficiently resolve convective motions but only marginally resolve those scales. Numerical simulations that marginally resolve convective scales have been referred to as convection permitting [15-19]. In most cloud-resolving models, a subgrid-scale (SGS) turbulence model such as those of Smagorinsky [20], Lilly [21], and Deardorff [22] is employed for parameterizing the effects of turbulence mixing. Klemp and Wilhelmson [23] used a type of the SGS model of Deardorff [22] to represent the effects of unresolved turbulence mixing in their cloud model with the grid spacing of $1 \mathrm{~km}$. It should be mentioned that they recognized that the subgrid-scale modeling for turbulence mixing requires the existence of a grid scale within the inertial subrange and also noted that with their grid resolution the requirement is not satisfied. In general, SGS models should be used in the turbulent-flow simulations whose grid scale is within the turbulence inertial subrange. Bryan et al. [15] investigated the sensitivities of squall-line simulations on horizontal grid spacing by examining power spectral features. They argued that in order for a SGS turbulence model in convectionresolving simulations to appropriately perform as an eddy viscosity the grid spacing on the order of $100 \mathrm{~m}$ is required for the simulations. Takemi and Rotunno [24] examined the effects of SGS eddy viscosity and numerical diffusion on convection simulations and showed that the numerical diffusion has a stronger impact than the eddy viscosity in common convection-resolving models with the grid spacing of $1 \mathrm{~km}$. In other words, the solutions of convectionresolving simulations may significantly be influenced by the unwanted effects of numerical diffusion. These studies discussed the diffusion effects in idealized simulations.

Skamarock [25] examined the effects of spatial filters (i.e., diffusion) that are both numerical and physical on the shortest model-resolved scales using kinetic energy spectra and showed that the spectral distribution is useful in identifying filtering effects. He then proposed that an effective resolution in which models can well represent physics is much larger than the grid scale $(\Delta x)$, that is, mostly at 6-7 $\Delta x$ scale due to various model filters. If the grid spacing of $1 \mathrm{~km}$ is employed for convection simulations, the scale that model can sufficiently resolve may lie in $6-7 \mathrm{~km}$. This scale obviously is not appropriate in representing each convective cloud. Therefore, it is considered that the simulation with the grid spacing on the order of $1 \mathrm{~km}$ is not actually convection resolving.

On the other hand, recent progresses in computational techniques and resources enable us to conduct a large-eddy simulation (LES) of shallow and deep cumulus convection [26-29]. Such a high-resolution simulation ensures that convective clouds are sufficiently and explicitly resolved. Therefore, an LES-type high-resolution numerical experiment is useful in examining the microscale dynamics of convection and the processes that include both shallow and deep convection. In addition, high-resolution simulations can be used in diagnosing the performance of physics parameterizations and further in developing new parameterizations.

The present study examines the representations of shallow and deep convection under two distinct stability conditions over a desert region with the use of the numerical simulation outputs obtained by Takemi [28]. The numerical simulations were an LES at the $100 \mathrm{~m}$ horizontal resolution, conducted with an idealized model setup, that is, a horizontally homogeneous basic state over a uniform flat surface; thus we can neglect the effects of surface heterogeneity that would generate small-scale eddies corresponding to the scale of the surface variability. With this modeling setup, the simulations are able to experimentally investigate the 
relationship between the initial stabilities and the representations of convection and associating dust transport. Spatial spectra are used in order to examine how small-scales are reproduced and how representative scales appear at various heights. From the results of the spectral analyses, we discuss a grid scale required for convection-resolving simulations of shallow and deep convection. Furthermore, a consequence of the representations of shallow and deep convection in simulations of dust transport is discussed.

\section{Model Setup and Numerical Experiments}

The numerical model used in the present analyses is a nonhydrostatic atmospheric model, the Advanced Regional Prediction System (ARPS) [30, 31]. The model includes full physics parameterizations, that is, cloud microphysics, SGS turbulence mixing, land-surface physics, and radiative transfer [31]. Details of the numerical experiments were described in Takemi [28]; a brief summary of the experiments is given in the following.

In order to perform high-resolution numerical experiments that explicitly resolve microscale eddies, the present experiments employed an LES model of Deardorff [22] for the parameterization of SGS turbulence mixing. The turbulence length scale depends on stability and has the same value both in the horizontal and in the vertical directions.

The model was configured in an idealized way as in Takemi et al. [32] in order to focus on the essential dynamics of shallow and deep convection. The case examined here is a fair-weather condition over an arid area in China, which was observationally examined by Yasui et al. [7]. This case was chosen because significant diurnal variability is seen and the assumption of horizontal homogeneity is regarded as a good approximation. The horizontally homogeneous basic state was determined with the use of a single sounding at a desert site in China. The Coriolis force was ignored in the governing equations because of its minor effects to microscales and of the intent to make the problem simpler.

The computational domain had a dimension of $40 \mathrm{~km}$ (east-west, the $x$ axis) $\times 10 \mathrm{~km}$ (north-south, the $y$ axis) $\times 11 \mathrm{~km}$ (vertical, the $z$ axis). Periodic condition was imposed at all the lateral boundaries, while a rigid lid condition was imposed at the upper boundary. The height of the upper boundary was set to $11 \mathrm{~km}$ because the numerical experiments were intended to simulate the diurnal variation of a springtime atmosphere over a Gobi Desert region in China, where the surface elevation is higher than $1000 \mathrm{~m}$ and the tropopause level was below the $10 \mathrm{~km}$ height above the ground level. In addition, a Rayleigh-type damping layer was set above the $9 \mathrm{~km}$ height in order to minimize the effects of the unwanted reflection of gravity waves at the upper boundary. The horizontal grid spacing $\Delta x$ was $100 \mathrm{~m}$, while the vertical grid spacing was varying with height from $20 \mathrm{~m}$ in the lowest level, increasing to $100 \mathrm{~m}$ at $2 \mathrm{~km}$ and further to $130 \mathrm{~m}$ at $8 \mathrm{~km}$, up to $240 \mathrm{~m}$ at the highest level. Although the horizontal grid spacing may seem to be marginal for conducting LES, this is considered to be sufficient for capturing well-organized structures of
PBL eddies and the size was used in other LES studies on convection [28].

In order to maintain the simulated fields not apart from the initial model state, the domain averaged profiles of horizontal velocities and water vapor mixing ratio were made to be relaxed toward the initial profiles with time scales of 3 and 24 hours, respectively, for momentum and moisture, which is similar to the method of Grabowski et al. [13]. This was done by adding the relaxation terms to the horizontal momentum and the water vapor conservation equations.

A single sounding located in an arid area of China was used to create the horizontally homogeneous basic state. Following the analyses of Yasui et al. [7] who examined the vertical profiles in a Gobi Desert site under fair-weather conditions during the Japan-China joint research program called Aeolian Dust Experiment on Climate Impact (ADEC) [33], we used the sounding data of Yinchuan, located in the southern part of the Gobi Desert, at 0000 UTC 13 April 2002 (the time corresponds approximately to 0600 local time (LT) relative to the local noon). The numerical experiment initialized with this sounding is referred to as EXP1 (Figure 1). The sounding data for EXP1 indicate a strong surface inversion layer capped by a stable boundary layer up to about the $2 \mathrm{~km}$ height. The moisture content sharply decreases with height, in accordance with the temperature profile. The strength of the low-level wind shear is relatively weak as compared to the other cases during the same month [7] and a severe storm case over a Gobi Desert area in China [34].

In addition to this initial profile, we examine a vertical structure obtained through a radiative-convective equilibrium simulation, which is referred to as a preliminary run. This preliminary run was initialized with the EXP1 profile and was conducted for 3 days after which a clear diurnal variation was represented. The numerical experiment initialized by this equilibrium state (which is the same as in Takemi et al. [32]) is referred to as EXP2, whose profiles are shown also in Figure 1. The vertical structure after the preliminary run has a strong surface inversion layer capped by a deep residual layer after the previous afternoon PBL, which is topped by a shallow inversion layer at about the $4.5 \mathrm{~km}$ height. The moisture content in the $2-5 \mathrm{~km}$ layer is significantly larger than that in the EXP1 profile, which is due to the previous daytime PBL development. The decrease of the moisture content with height up to the $4 \mathrm{~km}$ level is relatively small. The shear intensity is not enough to induce organization from individual cumulus clouds to mesoscale systems; thus, the present computational area of $40 \mathrm{~km}$ by $10 \mathrm{~km}$ is considered to be sufficient for representing deep convection under a low-shear condition considered here.

By using two initial stability conditions, we examine the diurnal variation of shallow convection and the transition from shallow to deep convection and compare the small scales in shallow and deep convection.

The emission, advection, mixing, and deposition of dust aerosols were computed by the emission and transport module developed by Takemi [35], which is embedded in the ARPS model. A prognostic equation of dust mixing ratio, which has the terms of advection, turbulence mixing, surface emission flux, gravitational settling, wet scavenging, and 


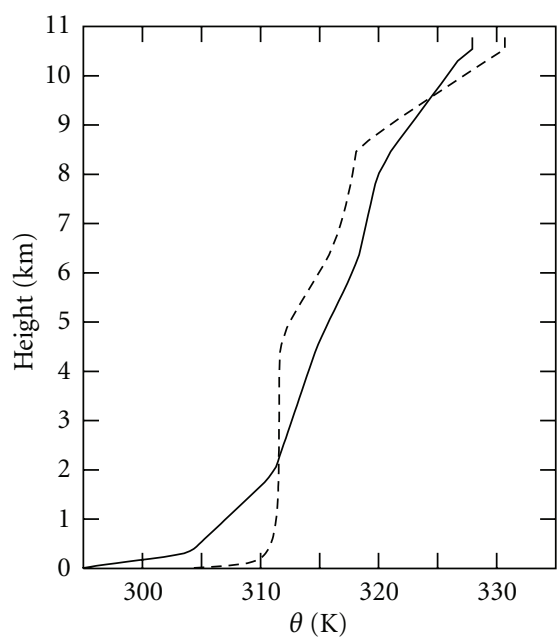

$\begin{array}{ll}- & \text { EXP1 } \\ --- & \text { EXP2 }\end{array}$

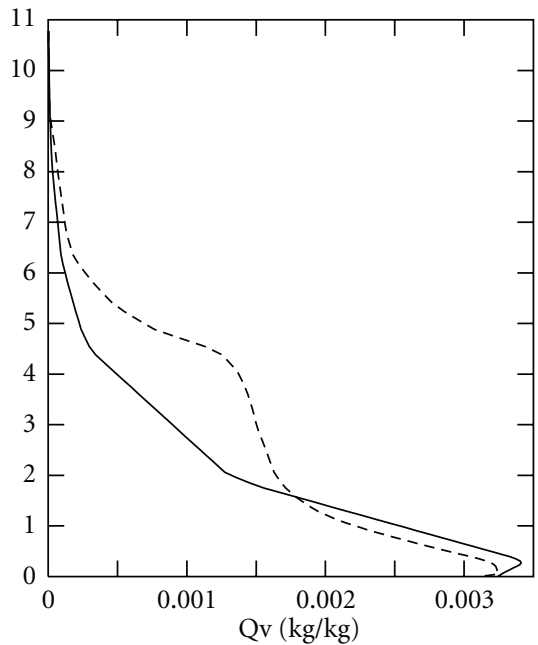

EXP1

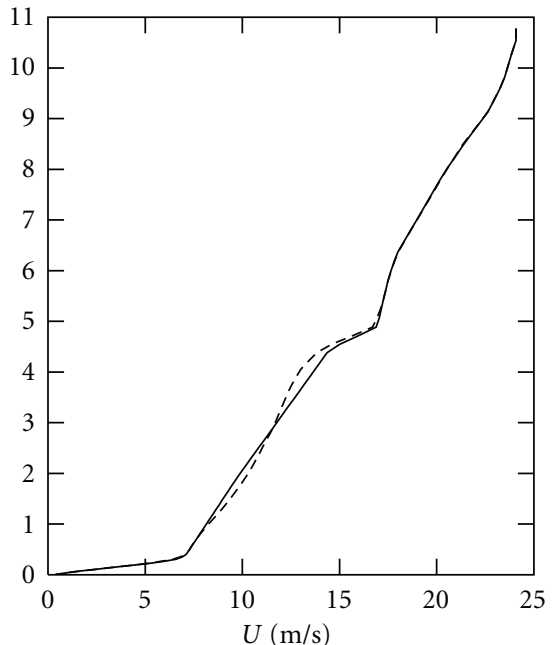

- EXP1

(a)

(b)

(c)

FIGURE 1: Initial vertical profiles of (a) potential temperature (in K), (b) water vapor mixing ratio (in $\mathrm{kg} \mathrm{kg}^{-1}$ ), and (c) horizontal wind speed (in $\mathrm{m} \mathrm{s}^{-1}, x$-component) for the EXP1 (solid lines) and the EXP2 cases (broken lines).

re-production due to evaporation of rain that captures dust, is added to the governing equation set of the ARPS model. The vertical dust flux at the surface is computed by the equation given by Liu and Westphal [36] in which the vertical flux is a function of the fourth power of friction velocity. The entire ground surface was assumed to be a desert category and to be erodible to dust emission if a critical friction velocity was exceeded. Following Liu and Westphal [36], the critical friction velocity for dust emission is set to be $0.6 \mathrm{~m} \mathrm{~s}^{-1}$, which is considered to be a typical value for the Mongolian and Chinese deserts. Wet scavenging is calculated by the relationship formulated as a function of rainfall intensity [37]. Since the present model includes a bulk-type microphysics parameterization for cloud and precipitation processes, the rainfall intensity is evaluated where rainwater mixing ratio appears and thus the present dust module accounts for both in-cloud and below-cloud scavenging. If dust is captured by rainwater, the dust falls at the terminal velocity of rainwater. Because rainfall evaporation below the cloud base is quite significant in the desert regions $[34,38]$, the present module takes into account the evaporation of rain that captures dust and the resulting re-production of dust from rain evaporation in the air. This dust module has been used for the simulations of convective transport of dust content in a severe weather condition [33] and fair-weather conditions $[26,30,31]$.

Both the EXP1 and EXP2 simulations were started at $0600 \mathrm{LT}$ and integrated in time with a time step of $0.75 \mathrm{~s}$ for 12 hours. The initial perturbation was given as random penitential temperature perturbations distributed below the $1 \mathrm{~km}$ height, with the maximum magnitude being $0.5 \mathrm{~K}$. The analyses are conducted for the model outputs with 300-s interval.

\section{Results}

Overall features of diurnal variation of convection are at first demonstrated. Figure 2 shows the diurnal variation of the vertical structures of the horizontally averaged atmosphere in terms of virtual potential temperature and turbulent kinetic energy (TKE). In the EXP1 case the variation of potential temperature indicates that the strongly stable surface layer as seen in Figure 1 is gradually eroded by solar surface heating and a convectively mixed state is then established and deepened. It is noted that in this case no cloud formation was simulated. The PBL evolution due to shallow convection activity can clearly be identified by TKE. In good agreement with the variation of potential temperature, the upper height of a layer with a significant amount of TKE gradually increases with time. The depth and strength of shallow convection, as diagnosed by TKE as well as virtual potential temperature, continuously increase and reach their peaks at around $1500 \mathrm{LT}$, after which occurs deep convective motion that is significantly weaker than the PBL motion. Despite the present idealized setting, the diurnal evolution of PBL seems to be in a fair agreement with the observed variation shown in Yasui et al. [7].

In the EXP2 case, on the other hand, the diurnal change is more pronounced. There is initially a strongly stable surface layer (see Figure 1), which is completely disappeared before 0900 LT. A mixed layer then develops from the surface and merges with the capping residual neutral layer to rapidly form a deep mixed layer. The mixed-layer convection immediately leads to the development of deep convective clouds. After the deep convection, the upper atmosphere becomes more stably stratified. In the afternoon, convective clouds sporadically develop; note that there was no organization of the deep convection to a larger system such as a mesoscale 


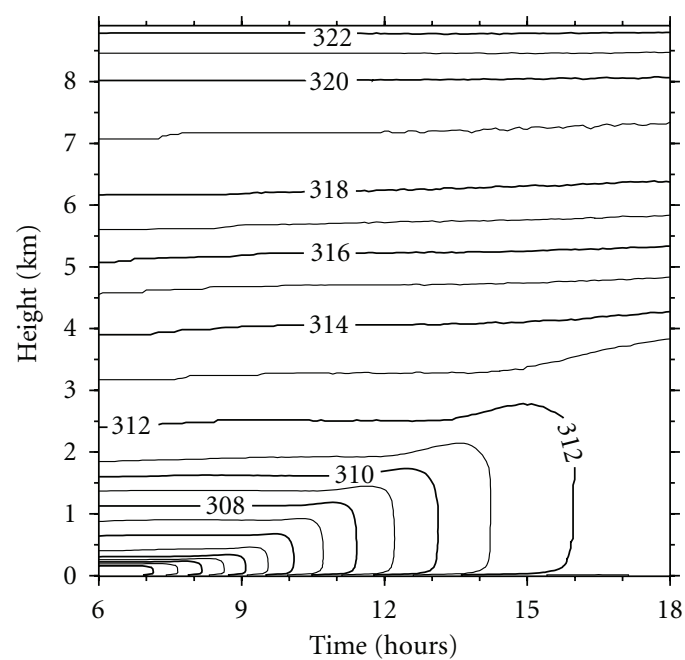

(a) EXP1: $\Theta v(K)$

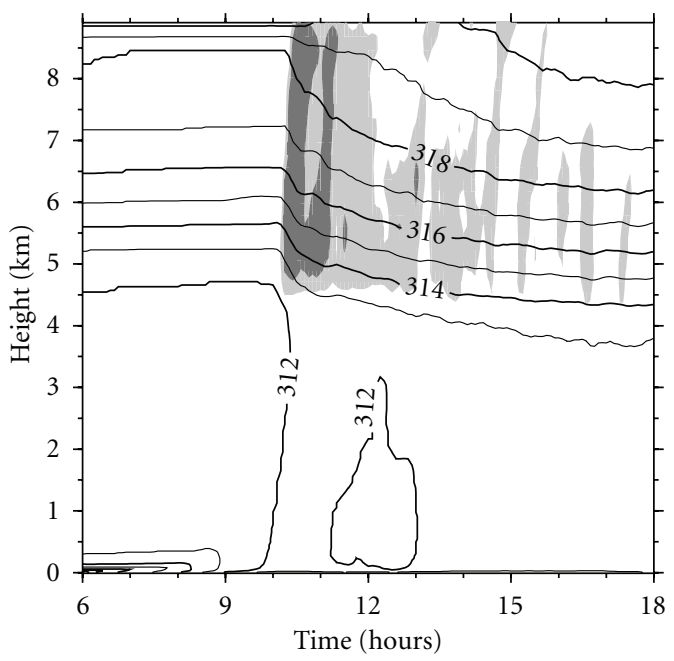

(c) EXP2: $\Theta v(K)$

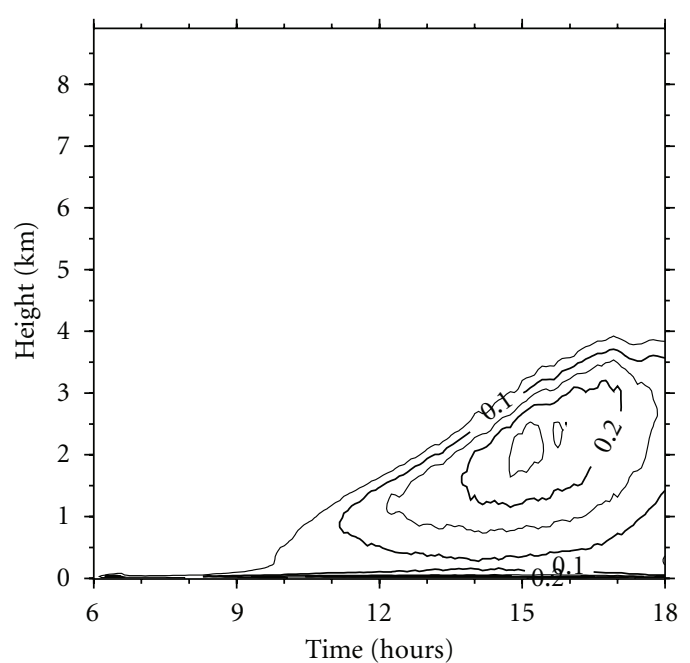

(b) EXP2: TKE $\left(\mathrm{m}^{2} / \mathrm{s}^{2}\right)$

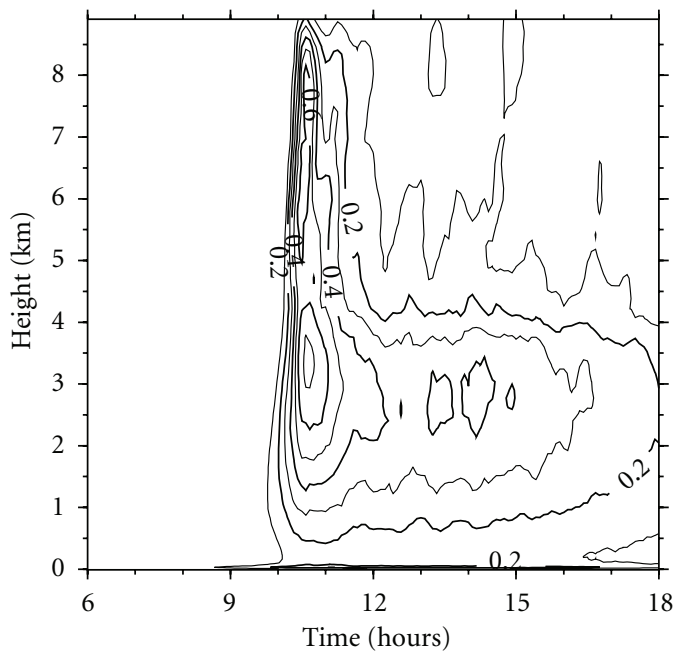

(d) EXP2: TKE $\left(\mathrm{m}^{2} / \mathrm{s}^{2}\right)$

FIGURE 2: Time-height section of horizontally averaged virtual potential temperature for (a) EXP1 and for (c) EXP2 (both contoured at 1-K interval) and turbulent kinetic energy for (b) EXP1 (contoured at $0.05-\mathrm{m}^{2} \mathrm{~s}^{-2}$ interval) and for (d) EXP2 (contoured at $0.1-\mathrm{m}^{2} \mathrm{~s}^{-2}$ interval). In (c) the region with cloud water plus ice mixing ratio of $0.025-0.05 \mathrm{~g} \mathrm{~kg}^{-1}$ is lightly shaded and the region with the mixing ratio greater than $0.05 \mathrm{~g} \mathrm{~kg}^{-1}$ is darkly shaded.

convective system. This diurnal development can also be seen in terms of TKE; however, the TKE evolution in EXP2 is significantly different from that in EXP1. In contrast to the TKE evolution in EXP1, the strength of deep convection in this case is comparable to, or even larger than, that of shallow convection. Due to the strong deep convection, the peak values of TKE in PBL are more than twice as large as those for the EXP1 case.

Spatial patterns of vertical motion fields near the surface layer, within the PBL, and at a midtropospheric level are examined here. Figure 3 demonstrates the horizontal cross sections of vertical velocity for the EXP1 case at the heights of $200 \mathrm{~m}, 2 \mathrm{~km}$, and $6 \mathrm{~km}$ at times when the PBL is developing $(0900 \mathrm{LT})$ and when the PBL is well developed (1500 LT). Note that the contour intervals are different with each other among the panels. At 0900 LT, a turbulent state is seen only at the $200 \mathrm{~m}$ level, while wavy features appear at the higher levels. This is due to the result that, as indicated in Figure 2, the top of the mixed layer is at around $400 \mathrm{~m}$ at 0900 LT. The structure of the turbulent state seems to be weakly aligned in the $x$-direction, which is probably due to an environmental weak westerly shear. The dominance of wavy patterns at the $2 \mathrm{~km}$ and $6 \mathrm{~km}$ levels is due to the stable state of the atmosphere above the mixed layer.

In Figure 3 a turbulent state is clearly seen at the level of $2 \mathrm{~km}$ as well as $200 \mathrm{~m}$ at $1500 \mathrm{LT}$ when the mixed-layer top reaches above the $2.5 \mathrm{~km}$ level (Figure 2). Updraft velocities at the $2 \mathrm{~km}$ level are much stronger at $1500 \mathrm{LT}$ than at 0900 LT. Furthermore, the structure of the turbulent state at the $200 \mathrm{~m}$ level seems to be elongated in the $x$ direction, while the structure at the $2 \mathrm{~km}$ level appears to have cellular patterns. The vertical velocity field at the $6 \mathrm{~km}$ level has still a wavy pattern similar to that seen at $0900 \mathrm{LT}$, owing to the stable stability of the upper troposphere. 


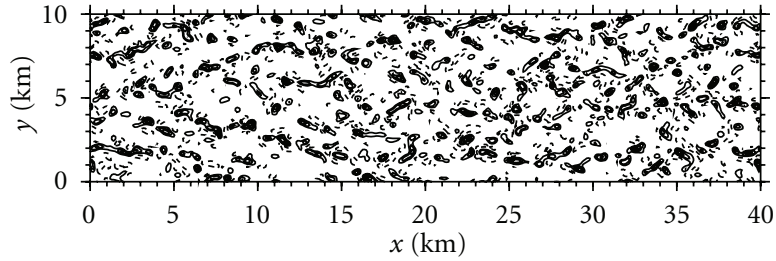

Contour interval $=6 E-01$

(a) $z=200 \mathrm{~m}, T=09 \mathrm{LT}$

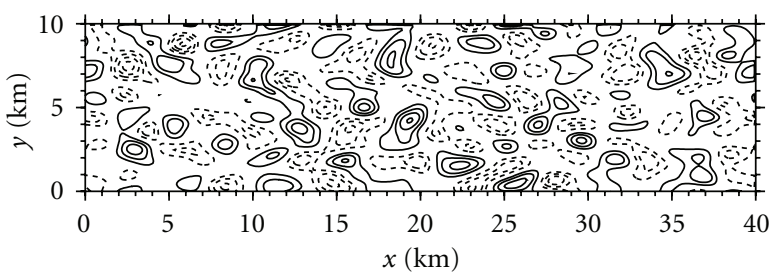

Contour interval $=1 E-01$

(c) $z=2 \mathrm{Km}, T=09 \mathrm{LT}$

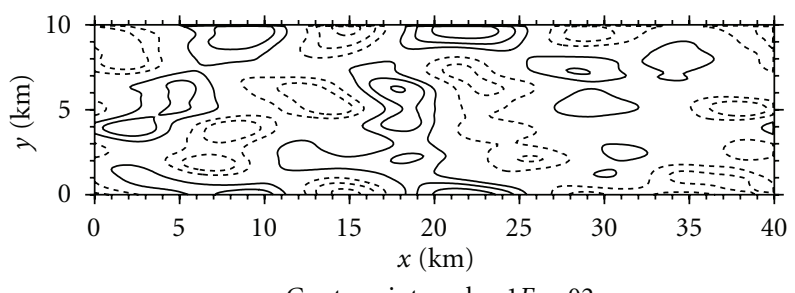

Contour interval $=1 E-02$

(e) $z=6 \mathrm{Km}, T=09 \mathrm{LT}$

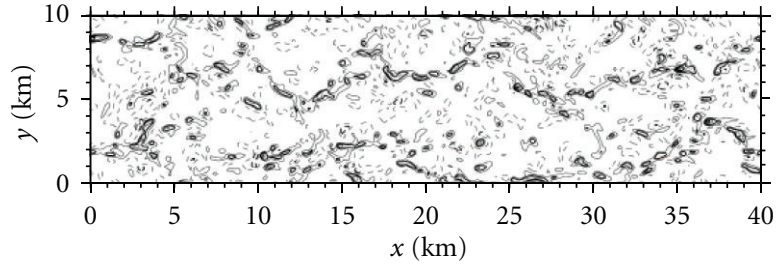

Contour interval $=1.2 E+00$

(b) $z=200 \mathrm{~m}, T=15 \mathrm{LT}$

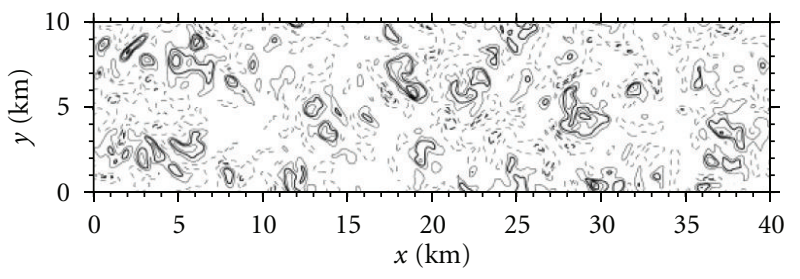

Contour interval $=1.5 E+00$

(d) $z=2 \mathrm{Km}, T=15 \mathrm{LT}$

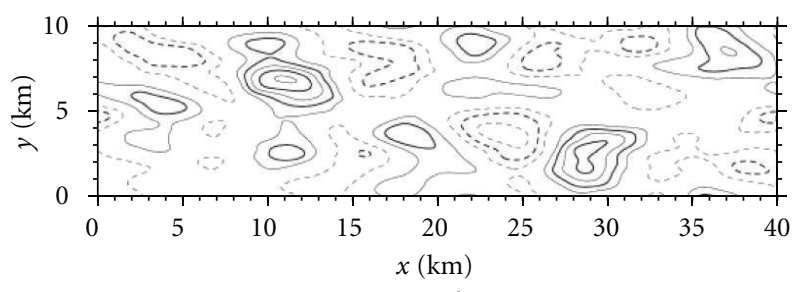

Contour interval $=5 E-01$

(f) $z=6 \mathrm{Km}, T=15 \mathrm{LT}$

Figure 3: Horizontal cross-section of vertical velocity in the EXP1 case at $200 \mathrm{~m}$ height at (a) $0900 \mathrm{LT}$ and at (b) $1500 \mathrm{LT}$, at $2 \mathrm{~km}$ height at (c) $0900 \mathrm{LT}$ and (d) $1500 \mathrm{LT}$, and at $6 \mathrm{~km}$ height at (e) $0900 \mathrm{LT}$ and at (f) $1500 \mathrm{LT}$. Contour intervals are indicated at the bottom of each panel. Positive (negative) values are indicated by solid (dashed) lines. The contour line of zero velocity is omitted.

The vertical motion field for the EXP2 case is shown in Figure 4. At 0900 LT a turbulent state is limited to the level of $200 \mathrm{~m}$ because the height of the mixed-layer top does not reach the $2 \mathrm{~km}$ height at this time (Figure 2). The comparison of the updraft fields at 0900 LT between EXP1 and EXP2 indicates that the turbulent state is more active in EXP2 than in EXP1. The spatial patterns at the upper levels show a wavy feature at $0900 \mathrm{LT}$. On the other hand, at $1500 \mathrm{LT}$ active turbulent eddies seem to dominate at all the levels shown in Figure 4. This is due to the development of both shallow PBL convection and deep cumulus convection (Figure 2). The overall intensity of updrafts is stronger in EXP2 than in EXP1. The updrafts at the $200 \mathrm{~m}$ level indicate a small-scale, stream-wise feature as in EXP1, while those at the $2 \mathrm{~km}$ level show a cellular structure that seems to be more organized than that in EXP1. It is seen that the areas of strong vertical motions at the levels of $200 \mathrm{~m}$ and $2 \mathrm{~km}$ correspond well with each other. This suggests that a vertically coherent structure exists, which is due to organized convective motion within the PBL. The pattern at the $6 \mathrm{~km}$ level also indicates a turbulent state, and the updraft strength is much stronger than that in EXP1.

In order to diagnose representative horizontal scales of shallow and deep convection simulated in EXP1 and EXP2, we examine the power spectra of the spatial variation of vertical velocity in the streamwise direction (i.e., the $x$ direction). In order to obtain the power spectral distribution, the spatial spectra are at first computed for the streamwise variation of vertical velocity at each $y$ coordinate, and then those spectra at each $y$ coordinate are averaged in the $y$ direction over the computational area. This procedure is exactly the same as in Takemi et al. [32]. The spectra are taken at levels of $200 \mathrm{~m}, 400 \mathrm{~m}, 1 \mathrm{~km}, 2 \mathrm{~km}$, and $6 \mathrm{~km}$ and at times when the mixed-layer structure is developing and is well developed.

In Figure 5, the spectra during the morning hours for the EXP1 case are indicated. At $0800 \mathrm{LT}$ the spectral peak at $z=$ $200 \mathrm{~m}$ is found at the $1 \mathrm{~km}$ scale. The power in the smaller scales gradually decreases with decreasing wavelength, and the spectral falloff becomes sharper in the shortest scales (i.e., less than about $500 \mathrm{~m}$ ). This sharp decrease in spectral power is considered to be resulted from the numerical filters embedded in the ARPS model (specifically, the fourth-order numerical diffusion) (Durran [39], Page 84, Figure 2.15; Takemi and Rotunno [24]). The spectral peak at higher levels shifts toward a larger scale: $1.5 \mathrm{~km}$ scale at the $400 \mathrm{~m}$ height, $4 \mathrm{~km}$ scale at the $1 \mathrm{~km}$ height, $5 \mathrm{~km}$ scale at the $2 \mathrm{~km}$ height, and $10 \mathrm{~km}$ scale at the $6 \mathrm{~km}$ height. At these heights, however, 


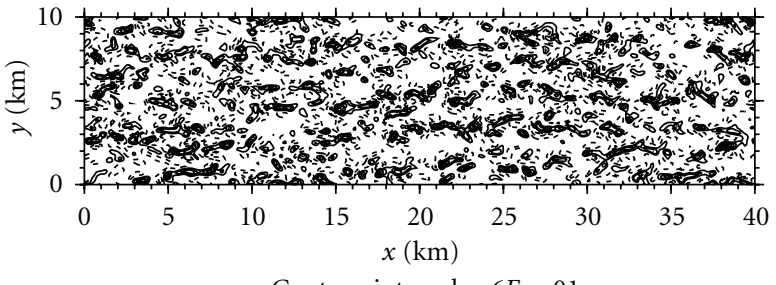

Contour interval $=6 E-01$

(a) $z=200 \mathrm{~m}, T=09 \mathrm{LT}$

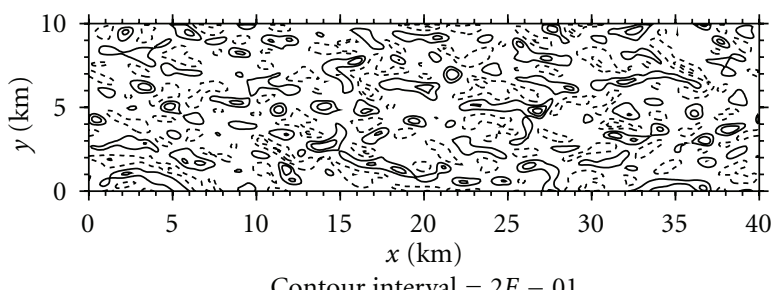

Contour interval $=2 E-01$

(c) $z=2 \mathrm{Km}, T=09 \mathrm{LT}$

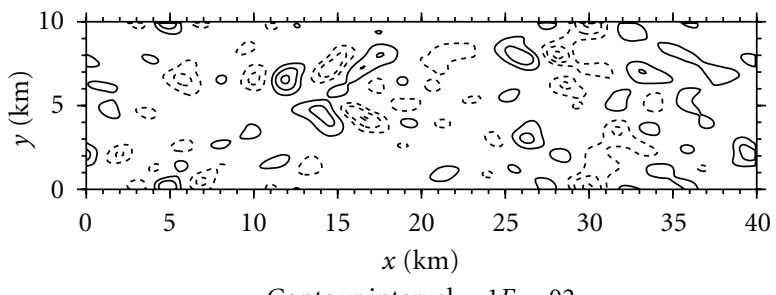

Contour interval $=1 E-02$

(e) $z=6 \mathrm{Km}, T=09 \mathrm{LT}$

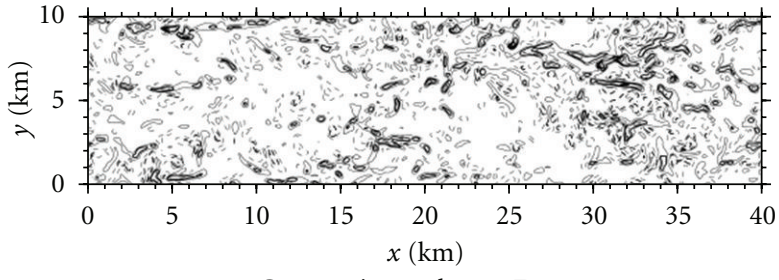

Contour interval $=1.2 E+00$

(b) $z=200 \mathrm{~m}, T=15 \mathrm{LT}$

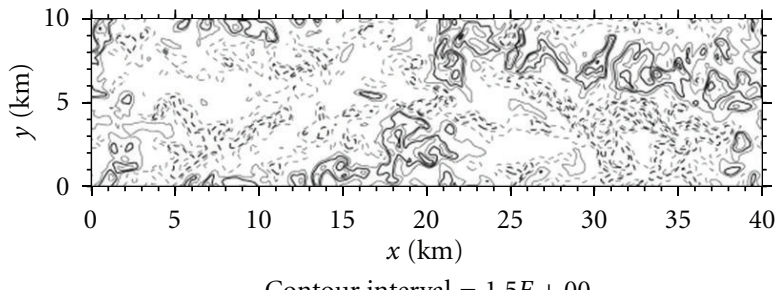

Contour interval $=1.5 E+00$

(d) $z=2 \mathrm{Km}, T=15 \mathrm{LT}$

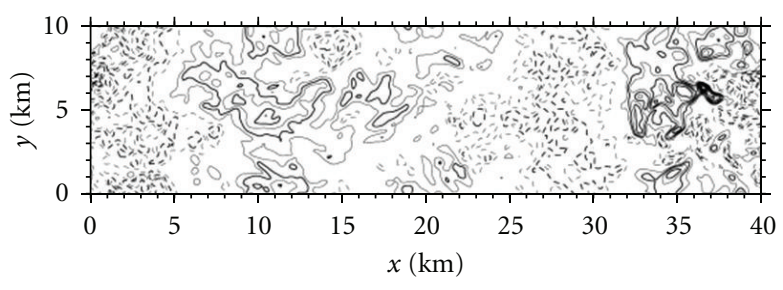

Contour interval $=5 E-01$

(f) $z=6 \mathrm{Km}, T=15 \mathrm{LT}$

Figure 4: The same as Figure 3 except for the EXP2 case. Note that the contour intervals are different from those in Figure 3 for (c).

the flow fields are not turbulent and thus the spectral falloff in shorter scales is not similar to that for the $200 \mathrm{~m}$ field.

At 0900 LT the scales of spectral peaks at the levels of $200 \mathrm{~m}$ and $400 \mathrm{~m}$ become closer with each other, while at 1000 LT and afterward not only the spectral peak but also the spectral shape seems to be similar with each other at the $200 \mathrm{~m}$ and $400 \mathrm{~m}$ levels. At 1100 LT the spectral shape at the $1-\mathrm{km}$ level is seen to match with those at the lower levels. The spatial scale at which spectral peak is seen increases with increasing the height above the $1 \mathrm{~km}$ level.

Figure 6 shows the temporal change of the spectral distribution for the EXP2 case. At 0800 LT and 0900 LT the spectral shapes seen in EXP2 appear to be similar to those in EXP1, while the differences of the EXP2 case from EXP1 become significant at $1000 \mathrm{LT}$ and afterward. This indicates that the temporal evolution of the spectral shape in EXP2 is much faster than that in EXP2, which is reflected from the different evolution of the development of shallow and deep convection as demonstrated in Figure 2. Owing to the development of deep convective clouds that have horizontal scales of about $10 \mathrm{~km}$ or greater, the spectral distributions at 1000 LT and afterward indicate that there is a significant power in the scales larger than $10 \mathrm{~km}$. The spectral shapes at the different levels at $1100 \mathrm{LT}$ indicate that there is a coherent feature in the vertical direction, generated by deep convective motions that closely couple with PBL shallow convection.

The spectral characteristics at the well-developed stage of PBL are then examined. Figure 7 compares the spectra at 1500 LT for the EXP1 and EXP2 cases. At the low levels of $200 \mathrm{~m}$ and $400 \mathrm{~m}$ the spectra for both experiments indicate that the peak is seen at the $1.5-2 \mathrm{~km}$ wavelengths. At the 1$2 \mathrm{~km}$ wavelengths in the spectral distributions, the spectral powers at the heights of $1 \mathrm{~km}$ and $2 \mathrm{~km}$ are comparable to those at the $200 \mathrm{~m}$ and $400 \mathrm{~m}$ heights. At the $1 \mathrm{~km}$ and $2 \mathrm{~km}$ heights, a spectral peak is seen at around the $3-\mathrm{km}$ wavelength, a little larger than those at the lower levels. The power in scales of around 5-10 km wavelengths seems to be larger in the EXP2 case than in EXP1 especially above the 1-km height, which is due to the presence of deep convective motion in the former case. It is also seen that depending on the existence of deep convective motion the spectral power not only in the largest scales but also in the short scales of less than $1 \mathrm{~km}$ at the 6-km height significantly differs between EXP1 and EXP2. These spectral features are quite consistent with the horizontal structures shown in Figures 3 and 4.

The present spectral analyses clearly indicate a degree to which the simulations resolve various scales of turbulent and convective motions not only in large scales but also in 


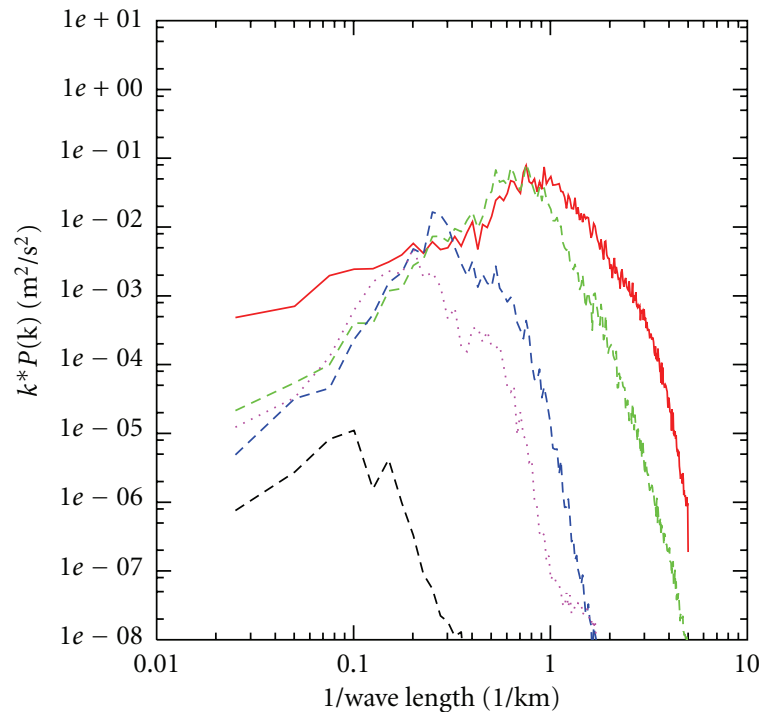

(a) $08 \mathrm{LT}$

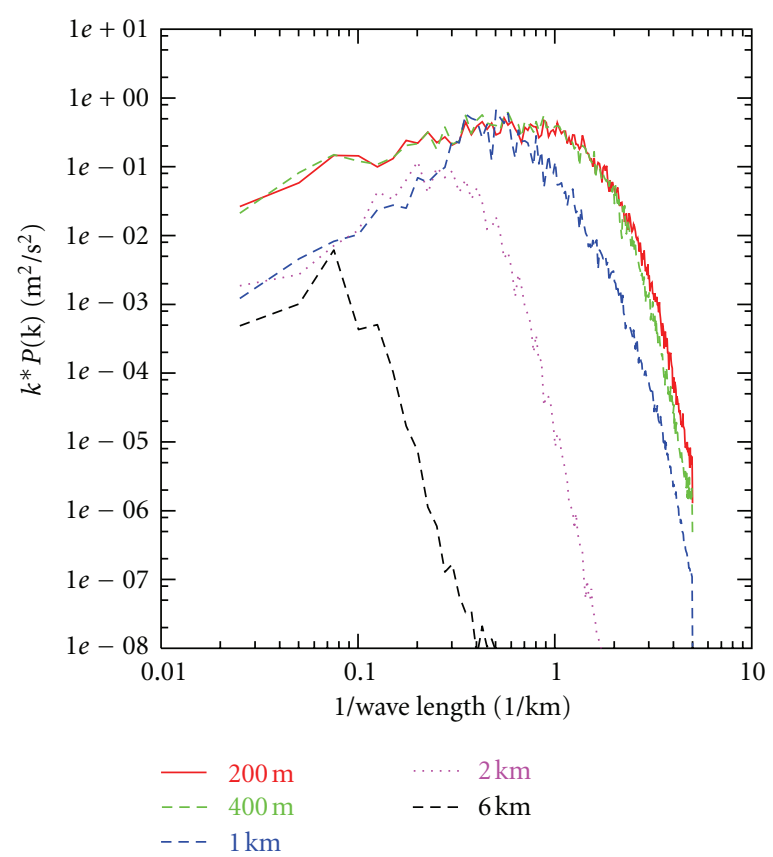

(c) $10 \mathrm{LT}$

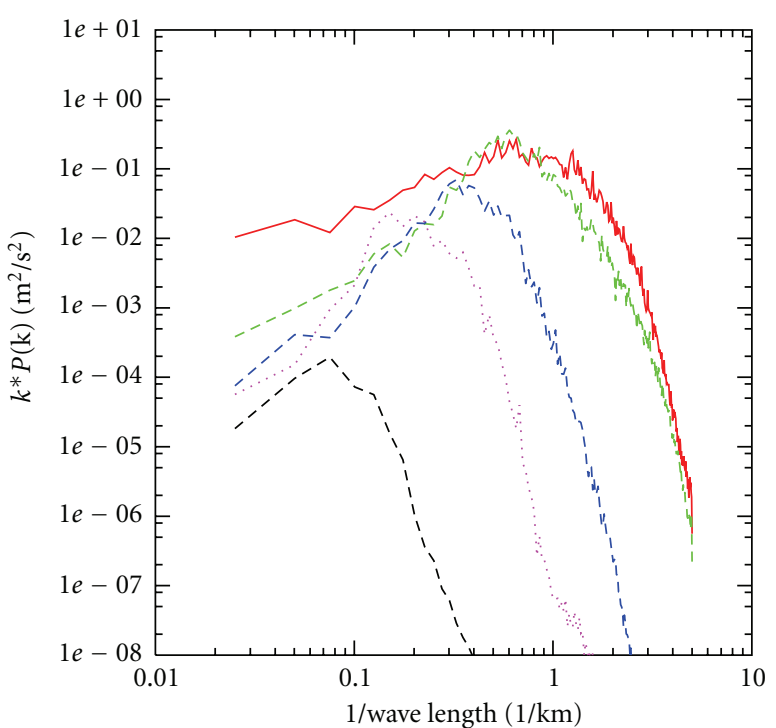

(b) 09 LT

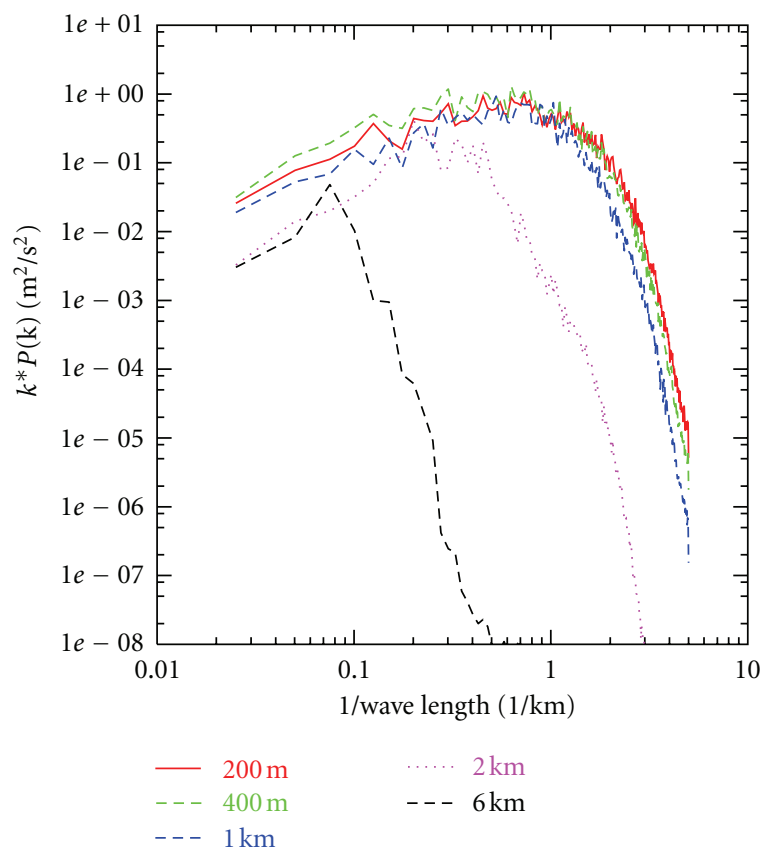

(d) $11 \mathrm{LT}$

FIGURE 5: Power spectral density distribution for the $x$-direction variation of vertical velocity at five levels for EXP1 at (a) 0800 LT, (b) 0900 LT, (c) 1000 LT, and (d) 1100 LT.

short scales of around $10 \Delta x$ (corresponds to $1 \mathrm{~km}$ in the present numerical experiments) or smaller. A consequence of the trans-port of dust aerosols through shallow and deep convection in terms of the numerical representations of convective motion is demonstrated here.

Figure 8 compares the vertical transport of dust content between EXP1 and EXP2. The figure indicates the diurnal variation of the vertical distributions of dust content and vertical dust flux averaged at each height. Owing to the difference in convective motion represented in the two experiments, the amount of transported dust as well as the intensity of vertical dust flux is significantly larger in the EXP2 case than in EXP1. In addition, the vertical extent of transported dust is much deeper in EXP2 than in EXP1, depending on the presence of deep convection. Therefore, the vertical extent of convective motion strongly regulates the transported dust content not only in the boundary layer but also in the free troposphere.

Takemi [28] examined the dependence of dust transport under a convective condition (which is the same as the EXP2 case) on the horizontal grid spacing by changing $\Delta x$ from $100 \mathrm{~m}$ to $4 \mathrm{~km}$. It was shown that with coarser resolutions 


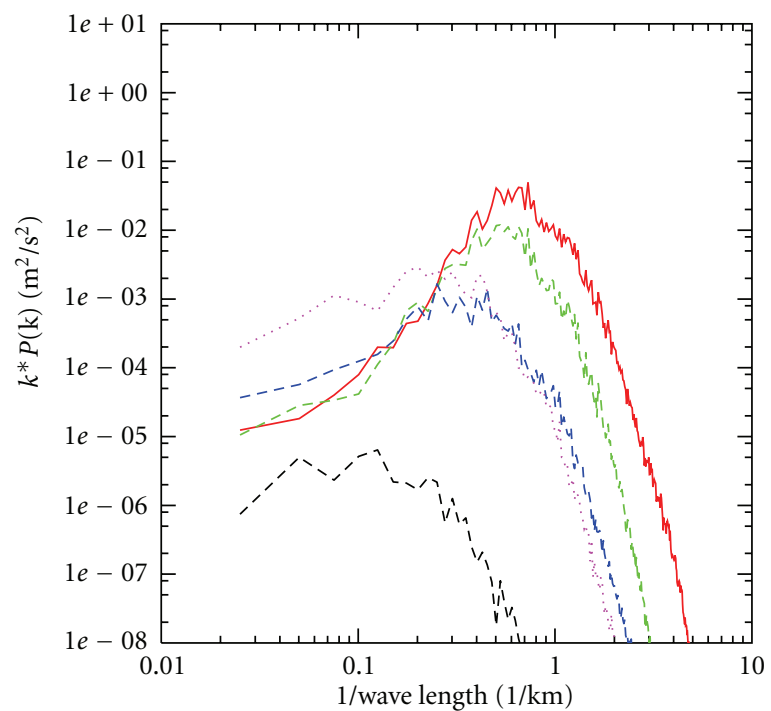

(a) $08 \mathrm{LT}$

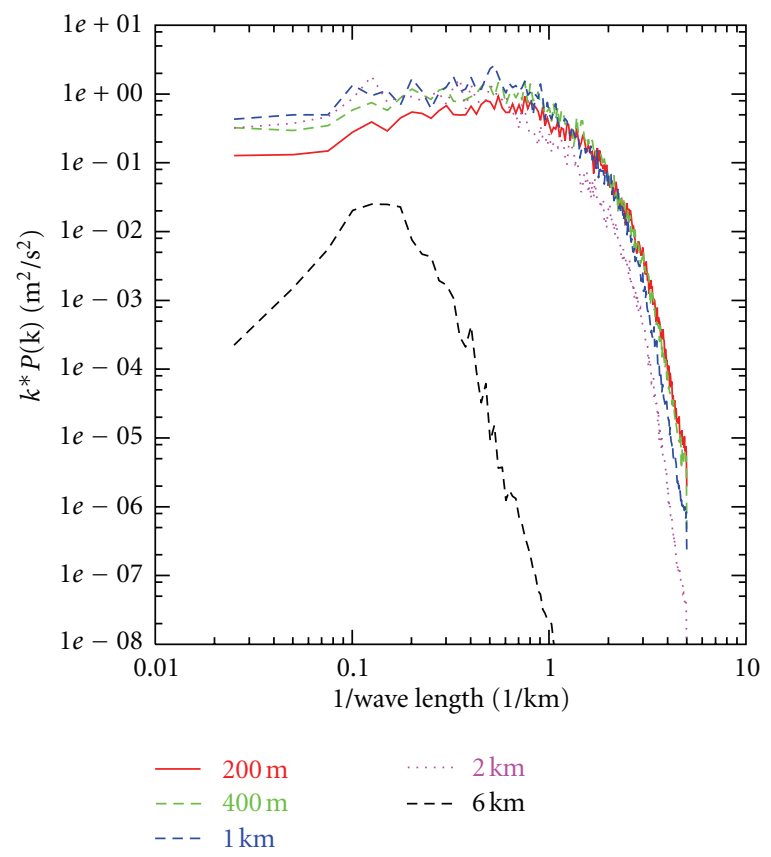

(c) $10 \mathrm{LT}$

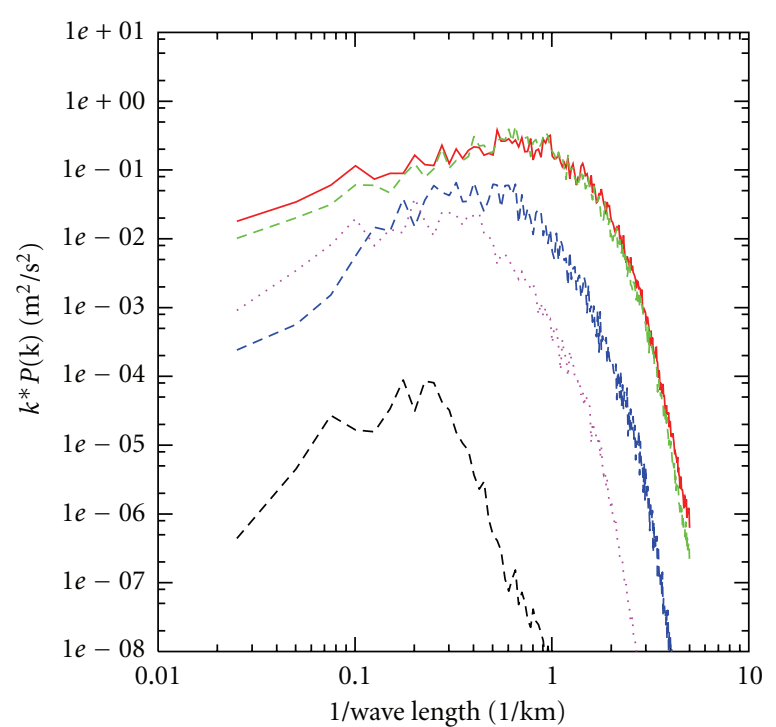

(b) $09 \mathrm{LT}$

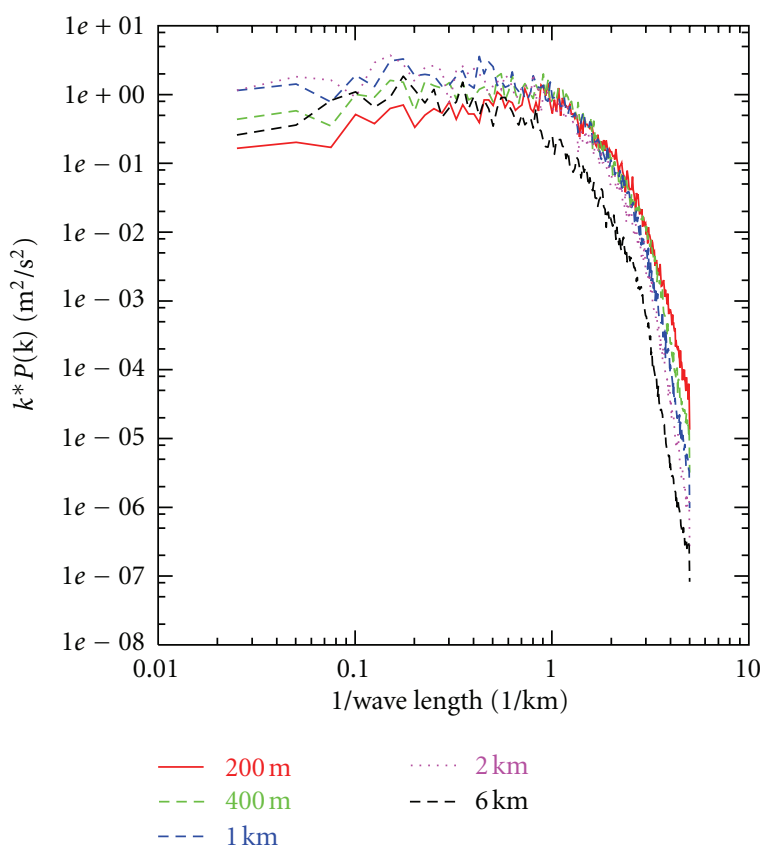

(d) $11 \mathrm{LT}$

Figure 6: The same as Figure 5 except for EXP2.

the development of not only shallow convection but also deep convection is poorly represented and that the poorly represented convective motion strongly affects the simulated amount of transported dust.

In order to clearly demonstrate the importance of the representation of shallow and deep convection in numerical simulations, the column total dust contents averaged over the computational area are calculated with the use of the dataset of the numerical experiments of Takemi [28] for the cases of $\Delta x=100 \mathrm{~m}, 500 \mathrm{~m}$, and $4 \mathrm{~km}$. Figure 9 compares the time series of the column total dust content for the present EXP2 simulation and the sensitivity simulations with the horizontal grid spacing of $500 \mathrm{~m}$ and $4 \mathrm{~km}$. The column dust in the EXP2 case indicates a gradual increase from 1030 LT until about $1600 \mathrm{LT}$, which reflects the diurnal evolution of the convective motion and the resultant dust transport as shown in Figure 8(b). The temporal change of the dust content in the $500 \mathrm{~m}$ resolution case also indicates a gradual increase similar to that seen in the EXP2 case despite that there are some differences in the initial time of dust increase and the final content at the end of the simulation time. On the contrary, the diurnal variation of the dust content in the $4 \mathrm{~km}$ resolution case is completely different from the changes in the EXP2 and the $500 \mathrm{~m}$ resolution case. The 


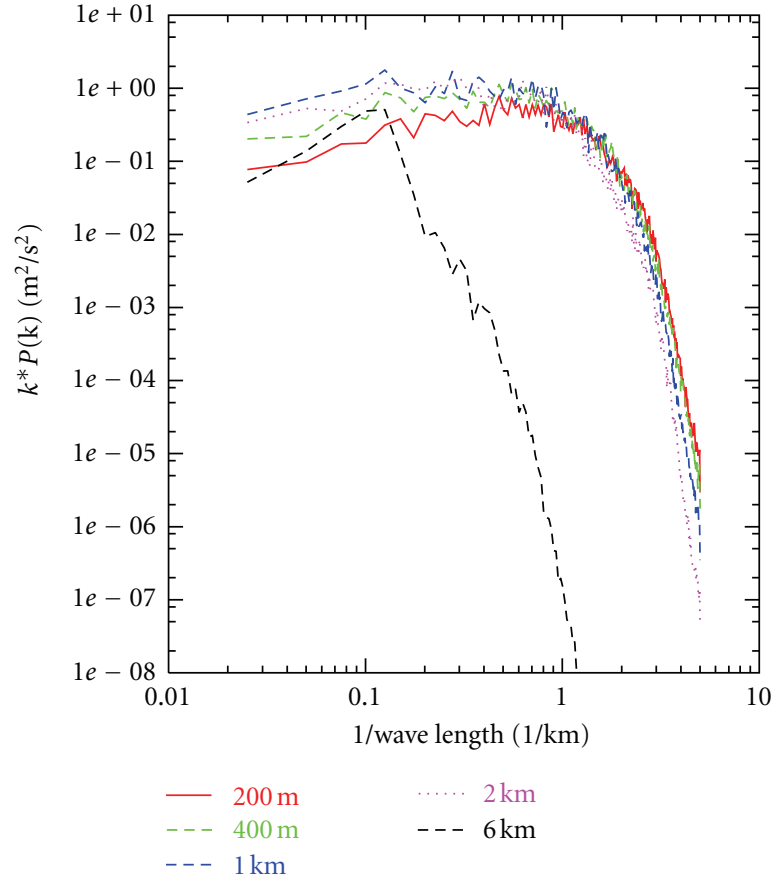

(a) EXP1: 15 LT

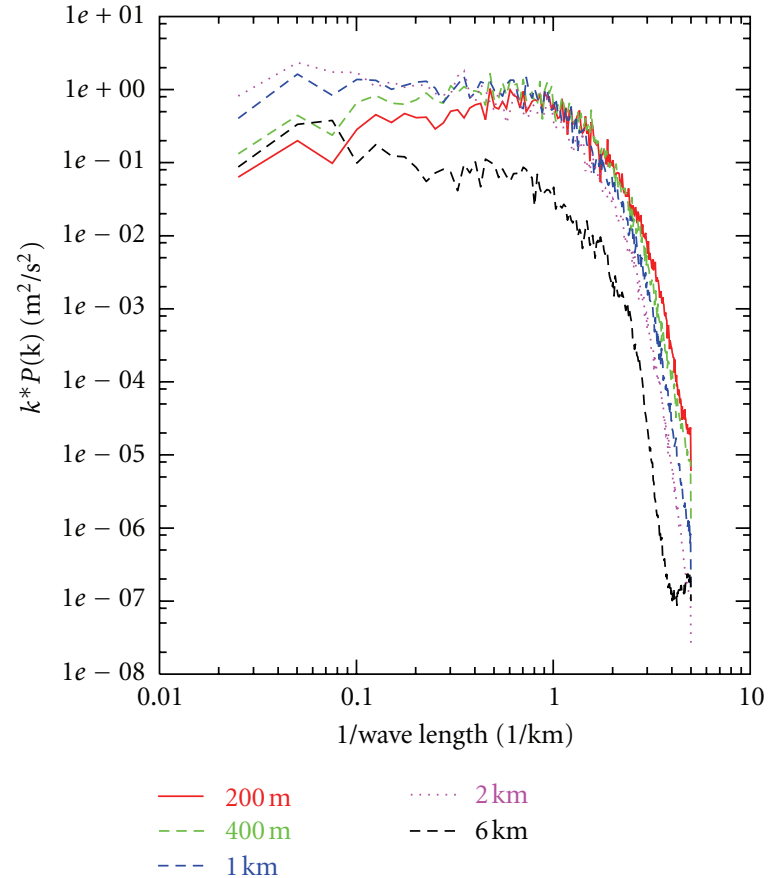

(b) EXP2: 15 LT

Figure 7: The same as Figure 5 except for at 1500 LT in (a) EXP1 and (b) EXP2.

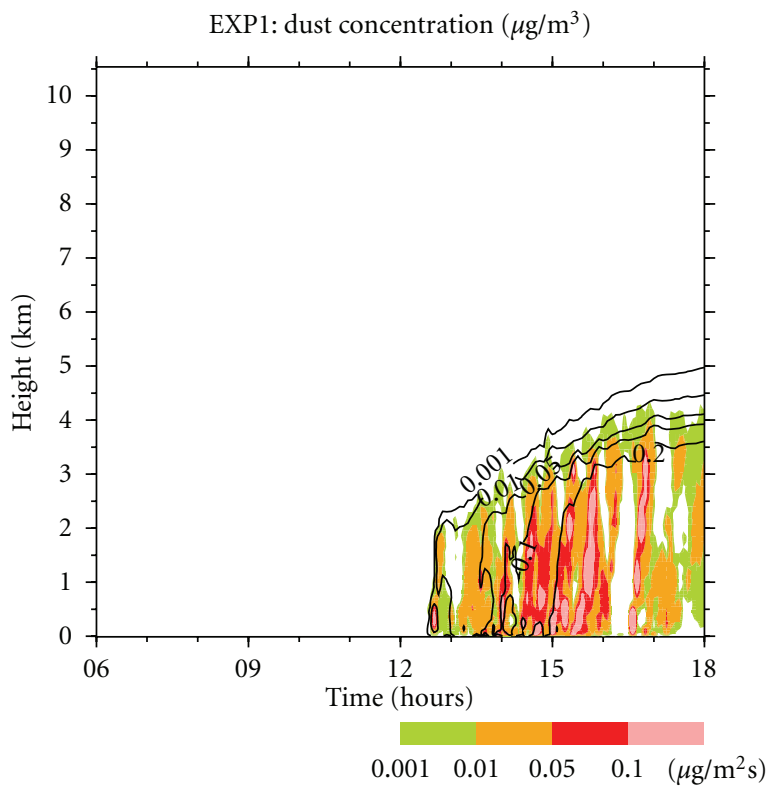

(a)

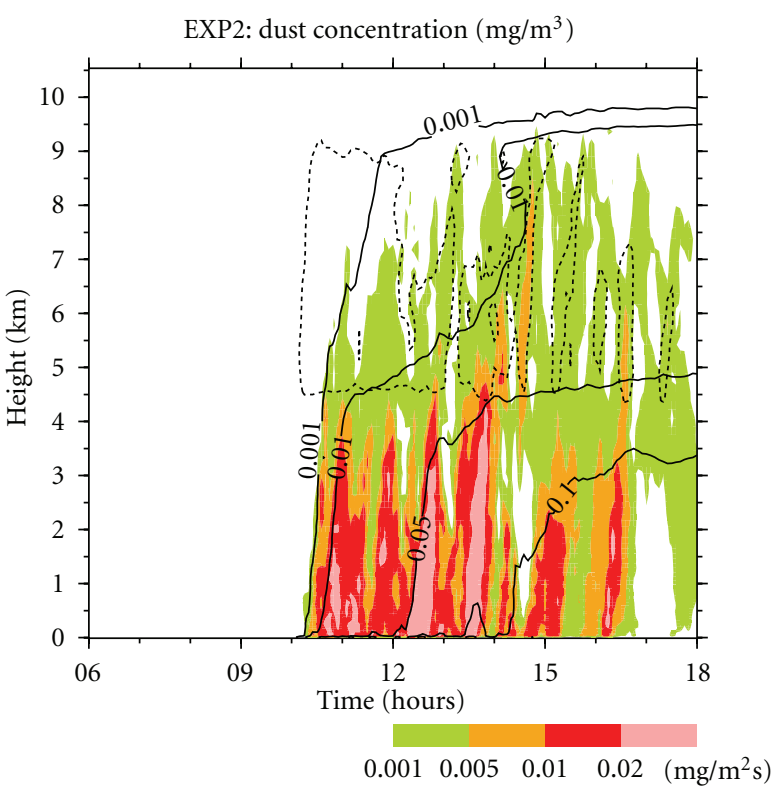

(b)

FIGURE 8: Time-height section of dust concentration (contoured) and vertical flux of dust (shaded, in $\mu \mathrm{g} \mathrm{m}^{-2} \mathrm{~s}^{-1}$ ) averaged over each height for (a) EXP1 and (b) EXP2. The contour intervals are (a) at 0.001, 0.01, 0.05, 0.1, and $0.2 \mu \mathrm{g} \mathrm{m}^{-3}$ and (b) at 0.001, 0.01, 0.05, and 0.1 $\mathrm{mg} \mathrm{m}^{-3}$. In (b) the cloud boundary is indicated by broken lines as a contour of cloud mixing ratio of $0.025 \mathrm{~g} \mathrm{~kg}^{-1}$.

increase of the dust content in the $4-\mathrm{km}$ resolution case is accomplished only within one hour during 1400 and 1500 LT. This difference in the temporal evolution of the $4 \mathrm{~km}$ resolution case is due to the lack of proper representations of shallow and deep convection. Actually, the $4 \mathrm{~km}$ resolution is not sufficiently fine to resolve convective motions. In other words, the poorly resolved behavior of convective motions leads to undesirable representation of dust transport under convective conditions.

The present study indicates that such dependence on horizontal resolution is closely related to the represented spatial scales of convective motion in numerical simulations. 


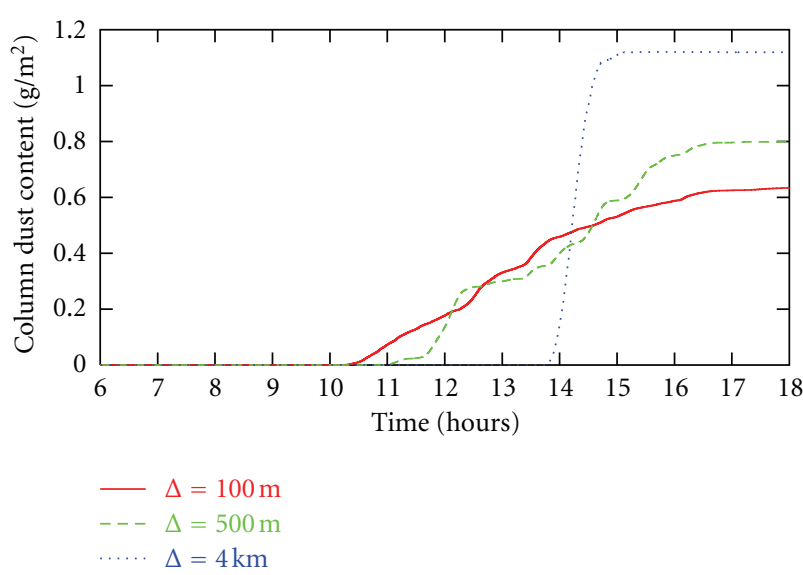

Figure 9: Column total dust content (in $\mathrm{g} \mathrm{m}^{-2}$ ) averaged over the computational area obtained from the EXP2 simulation (denoted as the red line) and the sensitivity simulations with the horizontal grid spacing of $500 \mathrm{~m}$ (the green line) and $4 \mathrm{~km}$ (the blue line).

In this way, the adequate representations of shallow and deep convection are critically important in simulating the transport of dust aerosols.

\section{Summary and Discussion}

Using the outputs of the numerical experiments of shallow and deep convection conducted by Takemi [28], we have examined the representations of convective motion in simulating the diurnal variation of PBL and the free troposphere under convectively unstable conditions over a desert area. The numerical experiments were set up under idealized conditions of a horizontally uniform basic state over a homogeneous and flat surface. The idealized setup was useful in focusing on the fundamental dynamics of convective motion over a desert area and examining the eddy scales that would be inherent in shallow and deep convection. The numerical model employed an SGS turbulence model for parameterizing turbulent mixing processes. Since the horizontal grid spacing was $100 \mathrm{~m}$ and the simulated fields indicated turbulent characteristics, the numerical experiments were regarded as LES.

Initialized with two contrasting stability conditions that both represent fair-weather settings over an arid surface (and thus no convective organization to the mesoscale is expected), the model reproduced characteristic diurnal evolution that depends on the initial stability. One case reproduced gradually developing PBL and associated shallow convection, while the other case simulated rapidly developing PBL that led to cumulus clouds and deep convective motion. Overall, shallow and deep convective motions seem to be sufficiently resolved with the grid spacing of $100 \mathrm{~m}$. The development and evolution of shallow and deep convection is significantly controlled by the initial stability. Considering that the horizontal size of convective motion increases with the increase of the vertical depth of the convection, the scale of convection is therefore regulated by the stability.
In order to identify the characteristic spatial scales of convective motion, spectral analyses were conducted for the spatial variation of vertical velocity. As investigated by Skamarock [25], examining the spectral distribution is a useful way to diagnose the characteristics of flow fields, the effects of model filters, and the representations of resolved scales. The representative scale (whose spectral power has a peak value) becomes larger with height during the development of PBL convection, but the scales among the different levels become similar with each other in the well-mixed PBL. Comparing the results of the case with only shallow convection occurring in the diurnal cycle (i.e., EXP1) and the case with both shallow and deep convection (i.e., EXP2), it was indicated that the shape of the spectra in scales smaller than $5 \mathrm{~km}$ looks similar (although there is a difference in power) and that the power in the larger scales is higher in the case with deep convection than in the case with shallow convection only.

From the spectral analyses, it was found that a significant amount of spectral power exists in the spatial scales of $1.5-2 \mathrm{~km}$ in the case with only shallow convection and in a slightly wider range of $1.5-3 \mathrm{~km}$ in the case with both shallow and deep convection. In other words, these scales are considered to be a key to perform simulations that explicitly resolve shallow and deep convection. Considering that an effective resolution is about $6 \Delta x$ [25] due to various filtering effects embedded in the model, a grid spacing of about $250-500 \mathrm{~m}$ may be required for the successful simulations of both shallow and deep convection. This grid size coincidently agrees with the resolution required for deep convection simulation discussed in Bryan et al. [15] from a viewpoint of subgrid-scale turbulence modeling and largeeddy simulation.

The present modeling setup is based on idealized conditions. Therefore, one might argue that the present analyses should be dependent on the experimental conditions. However, because of this present idealized setup, the present simulation is considered to reproduce a characteristic feature of shallow and deep convection inherent in the motion itself. Surface heterogeneity will generate turbulent eddies that are quite smaller than those produced in the present settings; however, even if the motion is initialized from the smaller-scale eddies, the atmospheric convection will be organized in a similar way as presented in this study. The grid spacing that should be used in the simulations explicitly resolving shallow and deep convection is actually an order of magnitude smaller than that used in common cloudresolving simulations [13] or cloud-permitting simulations [17-19].

\section{Acknowledgments}

The author would like to acknowledge the comments from the anonymous reviewers for improving the original paper. This work was also supported by a Scientific Research grant from Japan Society for Promotion of Sciences. The ARPS model was developed by the Center for Analysis and Prediction of Storms (CAPS), The University of Oklahoma, 
supported by the National Science Foundation and the Federal Aviation Administration through combined grant ATM92-20009. The GFD Dennou Library was used for drawing some of the figures and computing power spectral density.

\section{References}

[1] J. K. S. Ching and J. A. Alkezweeny, "Tracer study of vertical exchange by cumulus clouds.," Journal of Climate \& Applied Meteorology, vol. 25, no. 11, pp. 1702-1711, 1986.

[2] A. S. Goudie and N. J. Middleton, Desert Dust in the Global System, Springer, Berlin, Germany, 2006.

[3] Y. Shao, Physics and Modeling of Wind Erosion, Springer, Berlin, Germany, 2nd edition, 2008.

[4] C. Luo, N. Mahowald, and C. Jones, "Temporal variability of dust mobilization and concentration in source regions," Journal of Geophysical Research D, vol. 109, no. 20, Article ID D20202, 13 pages, 2004.

[5] J. Koch and N. O. Renno, "The role of convective plumes and vortices on the global aerosol budget," Geophysical Research Letters, vol. 32, no. 18, Article ID L18806, 5 pages, 2005.

[6] M. Holzer and T. M. Hall, "Low-level transpacific transport," Journal of Geophysical Research D, vol. 112, no. 9, Article ID D09103, 2007.

[7] M. Yasui, J. Zhou, L. Liu, T. Itabe, K. Mizutani, and T. Aoki, "Vertical profiles of aeolian dust in a desert atmosphere observed using lidar in Shapotou, China," Journal of the Meteorological Society of Japan, vol. 83, no. 3, pp. 149-171, 2005.

[8] M. Yasui, L. Liu, T. Itabe et al., "Dust profiles of the atmospheric boundary layer observed by a laser ceilometer at Shapotou, China in 2004," in Lidar Remote Sensing for Environmental Monitoring VII, U. N. Singh, T. Itabe, and D. N. Rao, Eds., vol. 6409 of Proceedings of SPIE, Goa, India, November 2006.

[9] M. Gamo, "Thickness of the dry convection and large-scale subsidence above deserts," Boundary-Layer Meteorology, vol. 79, no. 3, pp. 265-278, 1996.

[10] T. Takemi and T. Satomura, "Numerical experiments on the mechanisms for the development and maintenance of longlived squall lines in dry environments," Journal of the Atmospheric Sciences, vol. 57, no. 11, pp. 1718-1740, 2000.

[11] R. V. Cakmur, R. L. Miller, and O. Torres, "Incorporating the effect of small-scale circulations upon dust emission in an atmospheric general circulation model," Journal of Geophysical Research D, vol. 109, no. 7, Article ID D07201, 20 pages, 2004.

[12] R. L. Miller, J. Perlwitz, and I. Tegen, "Feedback upon dust emission by dust radiative forcing through the planetary boundary layer," Journal of Geophysical Research D, vol. 109, no. 24, Article ID D24209, 17 pages, 2004.

[13] W. W. Grabowski, X. Wu, and M. W. Moncrieff, "Cloud-resolving modeling of tropical cloud systems during phase III of GATE. Part I: two-dimensional experiments," Journal of the Atmospheric Sciences, vol. 53, no. 24, pp. 3684-3709, 1996.

[14] M. L. Weisman, W. C. Skamarock, and J. B. Klemp, "The resolution dependence of explicitly modeled convective systems," Monthly Weather Review, vol. 125, no. 4, pp. 527-548, 1997.

[15] G. H. Bryan, J. C. Wyngaard, and J. M. Fritsch, "Resolution requirements for the simulation of deep moist convection," Monthly Weather Review, vol. 131, pp. 2394-2416, 2003.

[16] G. H. Bryan, "Spurious convective organization in simulated squall lines owing to moist absolutely unstable layers," Monthly Weather Review, vol. 133, no. 7, pp. 1978-1997, 2005.
[17] C. Liu and M. W. Moncrieff, "Sensitivity of cloud-resolving simulations of warm-season convection to cloud microphysics parameterizations," Monthly Weather Review, vol. 135, no. 8, pp. 2854-2868, 2007.

[18] R. J. Trapp, B. A. Halvorson, and N. S. Diffenbaugh, “Telescoping, multimodel approaches to evaluate extreme convective weather under future climates," Journal of Geophysical Research D, vol. 112, no. 20, Article ID D20109, 2007.

[19] F. Zhang, N. Bei, R. Rotunno, C. Snyder, and C. C. Epifanio, "Mesoscale predictability of moist baroclinic waves: convection-permitting experiments and multistage error growth dynamics," Journal of the Atmospheric Sciences, vol. 64, no. 10, pp. 3579-3594, 2007.

[20] J. Smagorinsky, "General circulation experiments with the primitive equations. I: The basic experiment," Monthly Weather Review, vol. 91, pp. 99-164, 1963.

[21] D. K. Lilly, "On the numerical simulation of buoyant convection,” Tellus, vol. 14, pp. 148-172, 1962.

[22] J. W. Deardorff, "Stratocumulus-capped mixed layers derived from a three-dimensional model," Boundary-Layer Meteorology, vol. 18, no. 4, pp. 495-527, 1980.

[23] J. B. Klemp and R. B. Wilhelmson, "The simulation of threedimensional convective storm dynamics," Journal of the Atmospheric Sciences, vol. 35, pp. 1070-1096, 1978.

[24] T. Takemi and R. Rotunno, "The effects of subgrid model mixing and numerical filtering in simulations of mesoscale cloud systems," Monthly Weather Review, vol. 131, pp. 2085-2101, 2003, Corrigendum, vol. 133, pp. 339-341, 2005.

[25] W. C. Skamarock, "Evaluating mesoscale NWP models using kinetic energy spectra," Monthly Weather Review, vol. 132, no. 12, pp. 3019-3032, 2004.

[26] M. Khairoutdinov and D. Randall, "High-resolution simulation of shallow-to-deep convection transition over land," Journal of the Atmospheric Sciences, vol. 63, no. 12, pp. 3421-3436, 2006.

[27] A. Cheng and K. M. Xu, "Simulation of shallow cumuli and their transition to deep convective clouds by cloud-resolving models with different third-order turbulence closures," Quarterly Journal of the Royal Meteorological Society, vol. 132, no. 615, pp. 359-382, 2006.

[28] T. Takemi, "An eddy-resolving simulation of the diurnal variation of fair-weather convection and tracer transport," Atmospheric Research, vol. 89, no. 3, pp. 270-282, 2008.

[29] G. Matheou, D. Chung, L. Nuijens, B. Stevens, and J. Teixeira, "On the fidelity of large-eddy simulation of shallow precipitating cumulus convection," Monthly Weather Review, vol. 139, pp. 2918-2939, 2011.

[30] M. Xue, K. K. Droegemeier, and V. Wong, “The Advanced Regional Prediction System (ARPS) - A multi-scale nonhydrostatic atmospheric simulation and prediction model. Part I: model dynamics and verification," Meteorology and Atmospheric Physics, vol. 75, no. 3-4, pp. 161-193, 2000.

[31] M. Xue, K. K. Droegemeier, V. Wong et al., "The Advanced Regional Prediction System (ARPS)—a multi-scale nonhydrostatic atmospheric simulation and prediction tool. Part II: model physics and applications," Meteorology and Atmospheric Physics, vol. 76, no. 3-4, pp. 143-165, 2001.

[32] T. Takemi, M. Yasui, J. Zhou, and L. Liu, "Role of boundary layer and cumulus convection on dust emission and transport over a midlatitude desert area," Journal of Geophysical Research D, vol. 111, no. 11, Article ID D11203, 2006.

[33] M. Mikami, G. Y. Shi, I. Uno et al., "Aeolian dust experiment on climate impact: an overview of Japan-China joint project 
ADEC," Global and Planetary Change, vol. 52, no. 1-4, pp. 142-172, 2006.

[34] T. Takemi, "Structure and evolution of a severe squall line over the arid region in Northwest China," Monthly Weather Review, vol. 127, no. 6, pp. 1301-1309, 1999.

[35] T. Takemi, "Explicit simulations of convective-scale transport of mineral dust in severe convective weather," Journal of the Meteorological Society of Japan, vol. 83, no. 3, pp. 187-203, 2005.

[36] M. Liu and D. L. Westphal, "A study of the sensitivity of simulated mineral dust production to model resolution," Journal of Geophysical Research D, vol. 106, no. 16, pp. 1809918112, 2001.

[37] D. L. Westphal, O. B. Toon, and T. N. Carlson, "A case study of mobilization and transport of Saharan dust," Journal of the Atmospheric Sciences, vol. 45, no. 15, pp. 2145-2175, 1988.

[38] T. Takemi, "Evaporation of rain falling below a cloud base through a deep atmospheric boundary layer over an arid region," Journal of the Meteorological Society of Japan, vol. 77, no. 2, pp. 387-397, 1999.

[39] D. R. Durran, Numerical Methods for Wave Equations in Geophysical Fluid Dynamics, Springer, Berlin, Germany, 1999. 

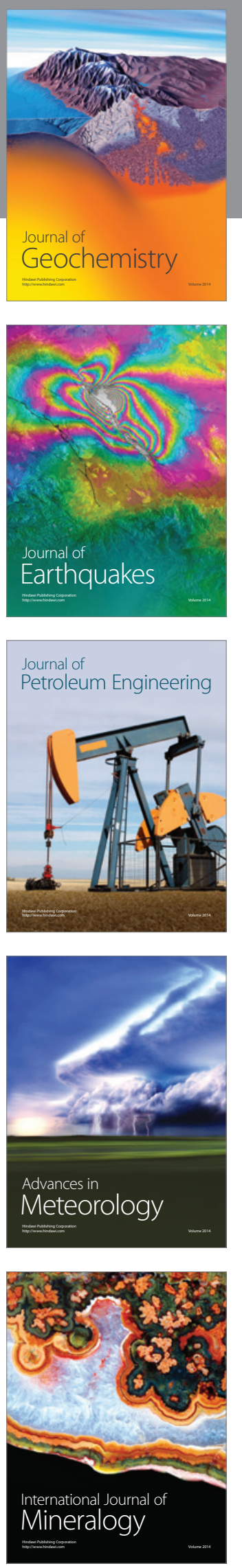
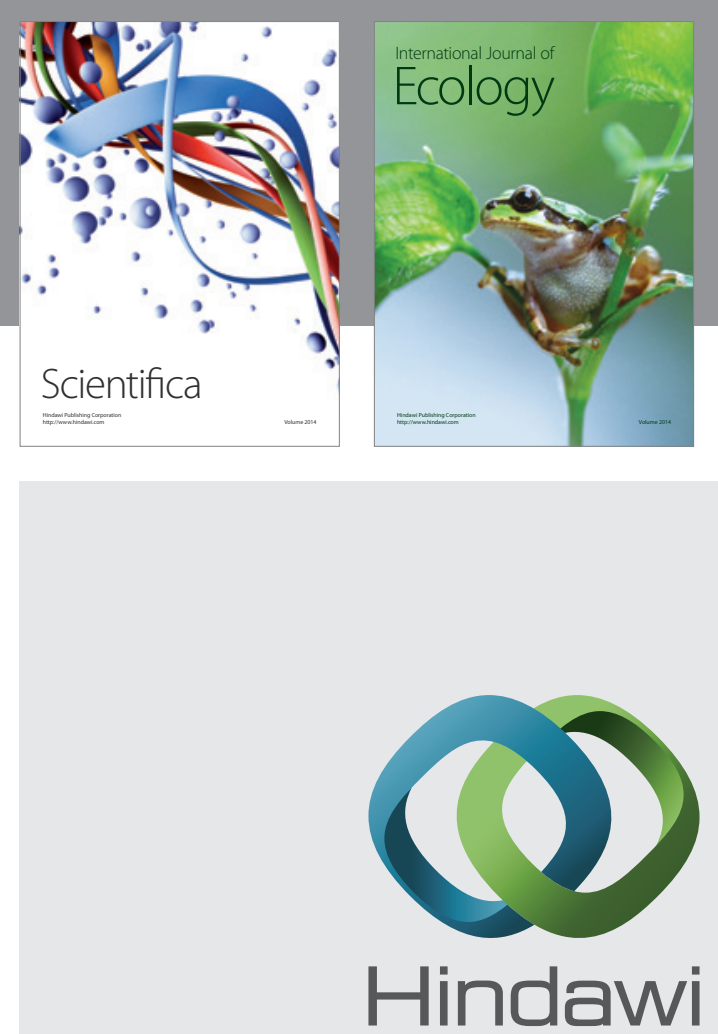

Submit your manuscripts at http://www.hindawi.com
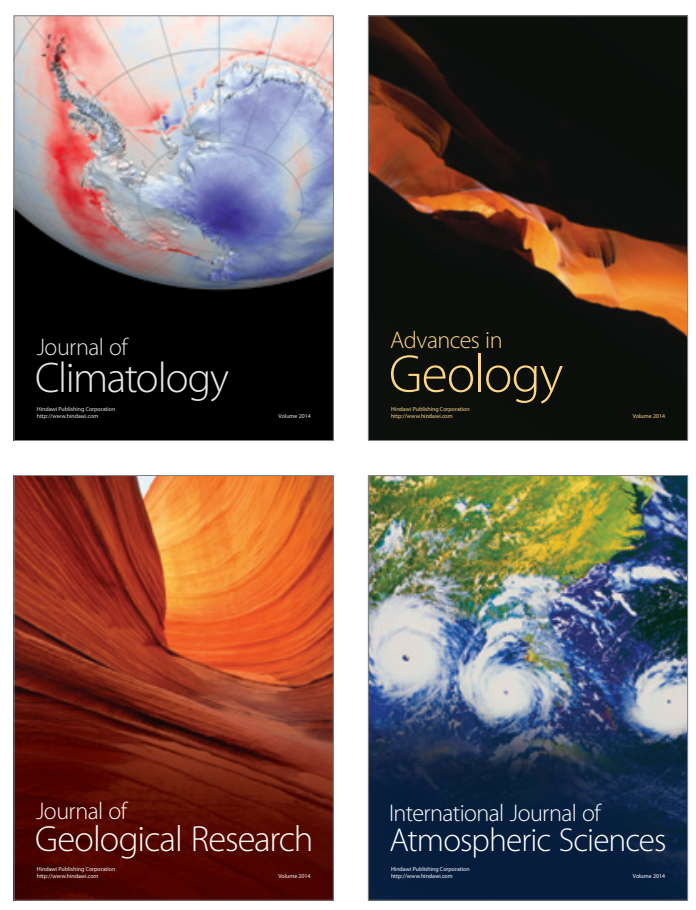
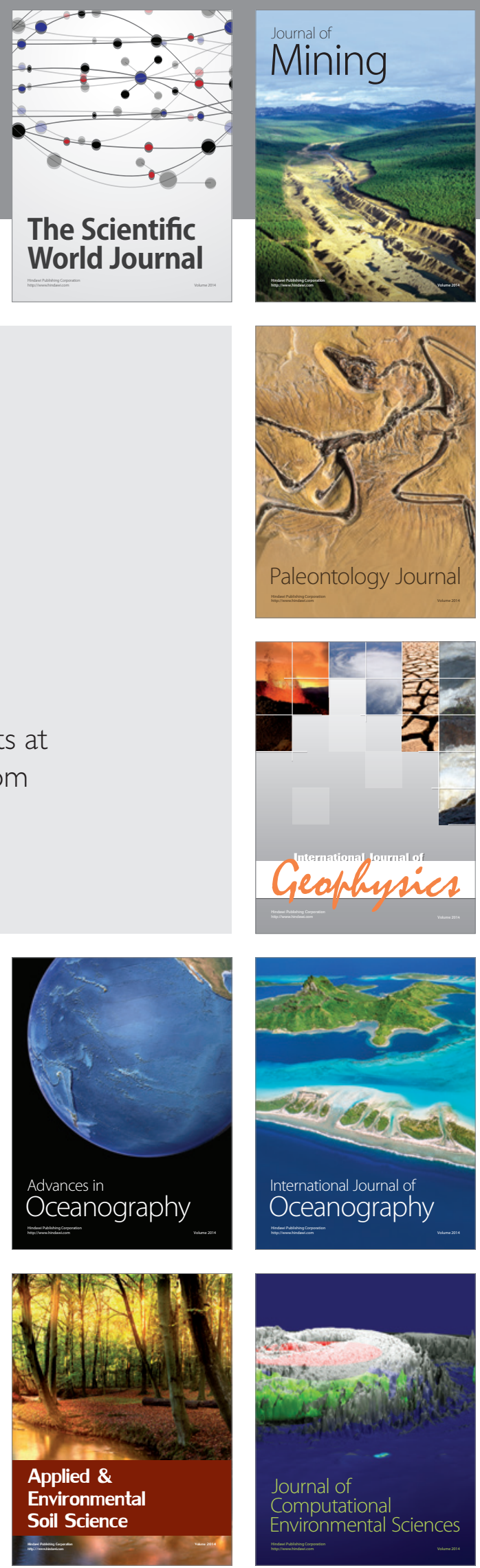